OPEN ACCESS

Edited by:

Jianjun Chen,

University of Florida, United States

Reviewed by:

Li Li,

University of New England, Australia

Robooni Tumuhimbise,

National Agricultural Research

Organisation, Uganda

Patrick Chiza Chikoti,

Zambia Agriculture Research Institute

(ZARI), Zambia

${ }^{*}$ Correspondence: Francis Manze

manzefrancis92@gmail.com

Specialty section:

This article was submitted to

Plant Breeding,

a section of the journal

Frontiers in Plant Science

Received: 11 January 2021

Accepted: 28 May 2021

Published: 21 June 2021

Citation:

Manze F, Rubaihayo P, Ozimati A,

Gibson P, Esuma W, Bua A, Alicai T, Omongo C and Kawuki RS (2021)

Genetic Gains for Yield and Virus

Disease Resistance of Cassava

Varieties Developed Over the Last

Eight Decades in Uganda.

Front. Plant Sci. 12:651992.

doi: 10.3389/fpls.2021.651992

\section{Genetic Gains for Yield and Virus Disease Resistance of Cassava Varieties Developed Over the Last Eight Decades in Uganda}

\author{
Francis Manze ${ }^{1,2 *}$, Patrick Rubaihayo ${ }^{1}$, Alfred Ozimati ${ }^{2}$, Paul Gibson', Williams Esuma², \\ Anton Bua ${ }^{2}$, Titus Alicai ${ }^{2}$, Chris Omongo ${ }^{2}$ and Robert S. Kawuki
}

${ }^{1}$ Department of Agricultural Production, Makerere University, Kampala, Uganda, ${ }^{2}$ National Crops Resources Research

Institute (NaCRRI), Kampala, Uganda

Achieving food security for an ever-increasing human population requires faster development of improved varieties. To this end, assessment of genetic gain for key traits is important to inform breeding processes. Despite the improvements made to increase production and productivity of cassava in Uganda at research level, there has been limited effort to quantify associated genetic gains. Accordingly, a study was conducted in Uganda to assess whether or not genetic improvement was evident in selected cassava traits using cassava varieties that were released from 1940 to 2019. Thirty-two varieties developed during this period, were evaluated simultaneously in three major cassava production zones; central (Namulonge), eastern (Serere), and northern (Loro). Best linear unbiased predictors (BLUPS) of the genotypic value for each clone were obtained across environments and regressed on order of release year to estimate annual genetic gains. We observed that genetic trends were mostly quadratic. On average, cassava mosaic disease (CMD) resistance increased by $1.9 \%$ per year, while annual genetic improvements in harvest index $(0.0 \%)$ and fresh root yield $(-5 \mathrm{~kg}$ per ha or $-0.03 \%$ per ha) were non-substantial. For cassava brown streak disease (CBSD) resistance breeding which was only initiated in 2003, average annual genetic gains for CBSD foliar and CBSD root necrosis resistances were $2.3 \%$ and $1.5 \%$, respectively. It's evident that cassava breeding has largely focused on protecting yield against diseases. This underpins the need for simultaneous improvement of cassava for disease resistance and high yield for the crop to meet its current and futuristic demands for food and industry.

Keywords: cassava breeding, cassava brown streak disease, cassava mosaic disease, yield related traits, genetic progress

\section{INTRODUCTION}

Cassava (Manihot esculenta Crantz) is a major staple crop in the tropics (Food and Agriculture Organization of the United Nations (FAOSTAT), 2019) owing to its transformative potential to spur economic growth, rural development and food security (Otekunrin and Sawicka, 2019). Indeed, over $60 \%$ of the world's cassava is produced in Africa (Food and Agriculture Organization of the United Nations (FAOSTAT), 2019), where its roots are processed into various forms (Shittu et al., 2016) to feed millions of people on a daily basis (Prakash, 2018). Within sub-Saharan Africa (SSA), 
cassava is recognized as a choice crop for climate change adaptation, as it performs reasonably well under prolonged droughts and marginal soils (Orek et al., 2020). It is for these reasons that cassava features predominantly in strategic plans for agricultural development of most SSA countries.

It suffices to note that cassava breeding efforts in Africa only began around 1930s (Storey and Nichols, 1938). During then, cassava mosaic disease (CMD) was a major breeding objective, as it had attained epidemic status on the continent (Legg and Thresh, 2000). Accordingly, pioneer cassava breeding efforts were initiated at Amani Research Station, Tanzania, to combat CMD. That breeding work involved interspecific hybridizations which led to the development and dissemination of cassava clones that were resistant to both CMD and cassava bacterial blight (Ortiz and Nassar, 2007).

The successful development of CMD resistant clones at Amani spurred an Africa-wide cassava research program that was instated at the International Institute of Tropical Agriculture (IITA) in Nigeria by 1971 (Hahn et al., 1980). Selected germplasm from Latin America, Asia and East Africa, along with cultivars from West Africa were collected to commence systematic genetic improvement of cassava at IITA (Hahn et al., 1980). Through that work, several elite genotypes with multiple resistances to prevalent pests and diseases and good culinary qualities were developed and disseminated to national breeding programs in Africa (Manyong et al., 2000).

In Uganda, CMD resistant varieties sourced from Tanzania formed a major part of the cassava production system between 1940s and 1980s (Otim-Nape et al., 2001), with clones such as Magana, Nyaraboke, Alado-Alado, Njure-Red, and Bamunanika predominating production in that period (Otim-Nape et al., 2001). It is should be noted that systematic cassava improvement in Uganda only started in the 1980s when a second wave of CMD caused by coinfection of African Cassava Mosaic Virus (ACMV) and the East African Cassava Mosaic Virus Uganda (EACMVUG) emerged (Gibson et al., 1996; Patil and Fauquet, 2009). Subsequently, elite cassava clones combining yield and resistance to CMD were sourced from IITA and evaluated in Uganda to select those with durable CMD resistance. Through this process, some outstanding varieties including NASE 1, NASE 2, and NASE 3 were identified and promoted for production in the early $1990 \mathrm{~s}$ (Ssemakula et al., 2000).

Released varieties were meant to be used for two main food products: "boiled or fried roots" that predominates central and western Uganda, and "flour-based meal" that predominates the eastern and northern parts of the country. As such, emphasis was initially placed on development of varieties characterized by high fresh root yield and dry matter content, multiple resistance to pests and diseases, starch quality, and low hydrogen cyanide (Ssemakula et al., 2000).

However, with the outbreak of cassava brown streak disease (CBSD) in early 2000s (Alicai et al., 2007), considerable efforts were diverted toward breeding for CBSD resistance, as the disease had then attained epidemic status and caused immense yield losses (Kawuki et al., 2016). CBSD damages the starch bearing part of cassava rendering it unfit for consumption, thereby causing huge economic losses and food insecurity (Hillocks et al.,
2001). In fact, from the time when CBSD attained epidemic status in Uganda, cassava production in the country declined drastically from 4.9 million tons (MT) in the 2000s to the current 2.6 MT (Food and Agriculture Organization of the United Nations (FAOSTAT), 2019).

Another notable change in the 2010s, was the consideration of gender and integration of preferred end-user quality traits in cassava breeding operations (Esuma et al., 2019; Iragaba et al., 2019). Currently, cassava breeding in Uganda is designed to enhance key traits that contribute toward increased resilience, nutrition and productivity for the benefit of stakeholders involved in the production-processing-marketingconsumption continuum.

Through these breeding efforts, 21 cassava varieties have been released between 1993 and 2015, and several other elite clones developed using genomic selection (Ozimati et al., 2019). Despite the improvements made to increase production and productivity of cassava in Uganda at research level, there has been limited effort to quantify associated genetic gains. Quantifying such gains would guide cassava breeding processes, especially now when the rapidly increasing population demands faster development and deployment of improved varieties. Therefore, the objective of this study was to determine the rate of genetic gain per year for cassava traits that have been selected for between 1940 and 2019 in Uganda.

\section{MATERIALS AND METHODS}

\section{Plant Material}

A total of 32 cassava varieties were used for this study (Table 1) and these were divided into four categories. Category one comprised local varieties; these arose from selections from Amani Research Program in Tanzania and were deployed for cultivation in Uganda between 1940s and1980s. Category two comprised varieties introduced from IITA and released in Uganda in the 1990s to combat CMD. Category three comprised a combination of varieties from IITA and Uganda; these were majorly developed for CMD resistance in the 2000s. Lastly, category four comprised varieties and elite clones developed in the 2010s to combat CBSD epidemic. All varieties were sourced from the Root Crops Research Program at the National Crops Resources Research Institute (NaCRRI) in Uganda, and had been maintained in Ngetta (northern Uganda), which is known to have low pressure of CBSD (Pariyo et al., 2015; Alicai et al., 2019). Sourcing planting materials from low disease pressure sites was important to ensure high vigor and uniform establishment.

\section{Description of Trial Environments}

All varieties were evaluated simultaneously at three environments representing major cassava agro-ecologies in Uganda, and this was done during the period April 2019 to May 2020. These environments were: Namulonge $\left(0.5232^{\circ} \mathrm{N}, 32.6158^{\circ} \mathrm{E}\right)$, Serere $\left(033^{\circ} 26^{\prime} 48.0^{\prime \prime} \mathrm{E}, 01^{\circ} 32^{\prime} 22.6^{\prime \prime} \mathrm{N}\right)$, and Loro $\left(32^{\circ} 28^{\prime} \mathrm{E}, 2^{\circ} 12^{\prime} \mathrm{N}\right)$. Namulonge is located in the Lake Victoria crescent at an altitude of $1163 \mathrm{~m}$ above sea level (asl), and is characterized by reddish sandy-clay loam soils (Fungo et al., 2011). Serere is located in 
TABLE 1 | Summary of attributes and origin of varieties used for genetic gain assessment.

\begin{tabular}{|c|c|c|c|c|c|}
\hline Code & Variety & Remarks & Status & Year & Special attributes at development and release \\
\hline 1 & NASE 1 & Introduced from IITA as TMS 60142 & Released & 1993 & CMDt, high DMC, and low HCN \\
\hline 2 & NASE 2 & Introduced from IITA as TMS 30337 & Released & 1993 & CMDt, good LR, and low HCN \\
\hline 3 & NASE 3 & Introduced from IITA as TMS 30572 & Released & 1993 & CMDt, CBSDt, good LR, and low HCN \\
\hline 4 & NASE 4 & Introduction from IITA & Released & 1999 & CMDr and low HCN \\
\hline 5 & NASE 5 & Introduction from IITA & Released & 1999 & CMDt and low HCN \\
\hline 6 & NASE 6 & Introduced from IITA as TMS 4 (2) 1425 & Released & 1999 & CMDr and low HCN \\
\hline 7 & NASE 9 & Introduced from IITA as 30555-17 & Released & 2003 & CMDt, CBSDs, and low HCN \\
\hline 8 & NASE 11 & Introduced from IITA as 92/NA-2 & Released & 2003 & CMDt, CBSDs, good LR, LUS, and low HCN \\
\hline 9 & NASE 12 & MH95/0414 & Released & 2003 & CMDr, CBSDs, low HCN, and desirable CQ \\
\hline 10 & NASE 13 & MH97/2961 & Released & 2011 & CMDr, CBSDs, high DMC, low HCN, and desirable CQ \\
\hline 11 & NASE 14 & MM96/4271 & Released & 2011 & CMDr, CBSDt, high DMC, low HCN, and desirable CQ \\
\hline 12 & NASE 15 & Derivative of TME14 & Released & 2011 & CMDr, CBSDt, high DMC, low HCN, and desirable CQ \\
\hline 13 & NASE 16 & Derivative of Bamunanika & Released & 2011 & CMDr, CBSDs, high DMC, low HCN, and desirable CQ \\
\hline 14 & NASE 18 & Derivative of TME14 & Released & 2011 & CMDr, CBSDt, high DMC, low HCN, and desirable CQ \\
\hline 15 & NASE 19 & Derivative of TME14 & Released & 2011 & CMDr, CBSDt, high DMC, low HCN, and desirable CQ \\
\hline 16 & NAROCASS 1 & NDL90/34HS & Released & 2015 & CMDr, CBSDt, high DMC, low HCN, and desirable CQ \\
\hline 17 & NAROCASS 2 & Introduced from Tanzania as MM06130 & Released & 2015 & CMDr, CBSDt, high DMC, and desirable CQ \\
\hline 18 & UG120124 & MM96/4271//MH04/2767 & Candidate & 2019 & CMDr, CBSDt, high DMC, and low HCN \\
\hline 19 & UG110166 & Introduction from Tanzania & Candidate & 2019 & CMDr, CBSDt, high DMC, and low HCN \\
\hline 20 & UG120024 & NASE 14/UG110043 & Candidate & 2019 & CMDr, CBSDt, high DMC, and low HCN \\
\hline 21 & UG120156 & Introduction from Tanzania & Candidate & 2019 & CMDr, CBSDt, high DMC, low HCN, and high RWF \\
\hline 22 & UG120183 & Introduction from Tanzania & Candidate & 2019 & CMDr, CBSDt, high DMC, and low HCN \\
\hline 23 & UG120198 & Introduction from Tanzania & Candidate & 2019 & CMDr, CBSDt, high DMC, and low HCN \\
\hline 24 & UG120193 & Introduction from Tanzania & Candidate & 2019 & CMDr, CBSDt, high DMC, low HCN, and high RWF \\
\hline 25 & UG110164 & Introduction from Tanzania & Candidate & 2019 & CMDr, CBSDt, high DMC, and low HCN \\
\hline 26 & Magana & Introduction from Tanzania & Landrace & 1940 & CMDt, quality flour and brew (popular in eastern Uganda) \\
\hline 27 & Njure Red & Introduction from Tanzania & Landrace & 1940 & CMDt, soft when boiled or fried (popular in central Uganda) \\
\hline 28 & Alado Alado & Introduction from Tanzania & Landrace & 1940 & CMDt, quality flour and brew (popular in northern Uganda) \\
\hline 29 & Bamunanika & Introduction from Tanzania & Landrace & 1940 & CMDt, soft when boiled or fried (popular in central Uganda) \\
\hline 30 & $\mathrm{Bao}$ & Introduction from Tanzania & Landrace & 1940 & CMDt, quality flour and brew (popular in northern Uganda) \\
\hline 31 & Omo & Introduction from Tanzania & Landrace & 1940 & CMDt, EM, sweet, quality flour and brew (popular in west Nile) \\
\hline 32 & Nyaraboke & Introduction from Tanzania & Landrace & 1940 & CMDt, soft when boiled or fried (popular in mid-western Uganda) \\
\hline
\end{tabular}

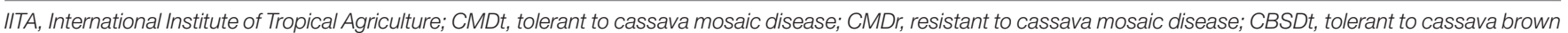

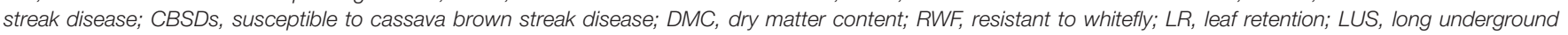

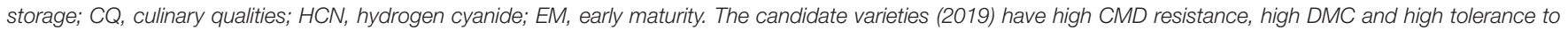
CBSD.

the semi-arid zones of eastern Uganda at an altitude of $1085 \mathrm{~m}$ asl with sandy loamy soils (Isabirye et al., 2004). Loro, on the other hand, has an altitude of $1063 \mathrm{~m}$ asl is also characterized by sandy loamy soils (Isabirye et al., 2004). Namulonge and Serere were specifically chosen because they are known to have high disease pressure for CMD and CBSD as well as high whitefly (vector) populations (Alicai et al., 2019). Loro was considered a suitable site for yield assessment owing to low disease pressure and vector populations for CBSD (Pariyo et al., 2015). The rainfall distribution at the three trial sites is bimodal with peaks in March to May and August to October, and mean annual precipitation ranges between 500 and $2800 \mathrm{~mm}$, while temperature ranges between $15^{\circ} \mathrm{C}$ and $30^{\circ} \mathrm{C}$ (Nsubuga et al., 2014).

\section{Trial Design and Management}

Trials at each site were planted in a randomized complete block design with two replications. Each clone was planted in five rows of six plants at $1 \times 1 \mathrm{~m}$ spacing, making a plot size of $20 \mathrm{~m}^{2}$ with 30 plants. Adjacent plots were separated by 2 -meter alleys to limit vegetative competition between varieties. Planting was done during the first growing season of 2019 (April) to ensure adequate soil moisture for sprouting. At 2 months after planting (MAP), six plants per plot were side-grafted with scions from highly infected TME 204, a standard CBSD susceptible check, to augment disease pressure for CBSD (Wagaba et al., 2013) at the three environments. All trials were conducted under standard agronomic practices for cassava (IITA, 1990).

\section{Data Collection}

Data on disease incidence and severity for CMD and CBSD were collected on each plant in a plot at 3 and 6 MAP. CMD severity was assessed on a scale of $1-5$; where $1=$ no visible disease symptoms, $2=$ mild chlorotic pattern on entire leaflets or mild distortion at base of leaflets, rest of leaflets appearing green and 
healthy, 3 = strong mosaic pattern on entire leaf, and narrowing and distortion of lower one-third of leaflets, $4=$ severe mosaic, distortion of two-thirds of leaflets and general reduction of leaf size, and $5=$ severe mosaic, distortion of four-fifths or more of leaflets, twisted and misshapen leaves (IITA, 1990). Similarly, CBSD foliar severity (CBSDfs) was scored on scale of $1-5$, where $1=$ no apparent symptoms, $2=$ slight foliar chlorosis but with no stem lesions, $3=$ pronounced foliar chlorosis and mild stem lesions with no die back, $4=$ severe foliar chlorosis and severe stem lesions with no die back, and $5=$ defoliation, severe stem lesions and die back (Gondwe et al., 2003).

At 12 MAP, trials were harvested to enable assessment of yield and other root attributes. All twelve plants within the net plot were harvested and partitioned into roots and above-ground biomass. Fresh root weight (FRW) and above-ground biomass were separately measured $\left(\mathrm{kg} \mathrm{plot}^{-1}\right)$ using a hanging weighing scale of $200 \mathrm{~kg}$ capacity. Harvest index (HI) was calculated as the ratio of FRW to total plant biomass as described by Kawano et al. (1978). Fresh root yield (FRY) (tones ha ${ }^{-1}$ ) was estimated by extrapolation of net plot root yields (Tumuhimbise et al., 2014). Root dry matter content (DMC) was determined by ovendrying of $100 \mathrm{~g}$ fresh samples at $80^{\circ} \mathrm{C}$ for $48 \mathrm{~h}$, as described by Kawano et al. (1987). Lastly, data on cassava brown streak disease root necrosis incidence (CBSDri), and severity (CBSDrs) was recorded on all harvested roots/plot. Data on CBSDrs was collected using a standard scale of $1-5$; where $1=$ no observable necrosis, $2=\leq 5 \%$ of root necrotic, $3=6$ to $25 \%$ of root necrotic, $4=26$ to $50 \%$ of root necrotic with mild root constriction, and while 5 showed greater than $50 \%$ of root necrosis with severe root constriction (Gondwe et al., 2003).

\section{Data Analysis}

For all measured traits, associated variance components were estimated by restricted maximum likelihood (Spilke et al., 2005). Effects of replicate nested in environment, variety, environment and variety by environment interaction were considered random, following the model below that was fitted using the lmer function in lme4 package (Bates et al., 2015) in R (R Core Team, 2019).

$$
Y_{i j k}=\mu+\left(R_{j}\right) E_{k}+V_{i}+E_{k}+V x E_{i k}+e_{i j k}
$$

where, $Y_{i j k}=$ phenotypic value; $\mu$ overall mean; $\left(R_{j}\right) E_{k}=$ random effect of replicate $j$ nested in $k^{\text {th }}$ environment such that $R_{j} \sim N\left(0, \sigma^{2}{ }_{j}\right) ; V_{i}=$ random effect of the $i^{\text {th }}$ variety with $V_{i} \sim N\left(0, \sigma^{2}{ }_{i}\right) ; E_{k}=$ random effect of $k^{\text {th }}$ environment with $E_{k} \sim$ $N\left(0, \sigma_{k}^{2}\right) ; V x E_{i k}=$ random interaction effect of $i^{t h}$ variety with $k^{\text {th }}$ environment such that $V x E_{i k} \sim N\left(0, \sigma^{2}{ }_{i k}\right)$; and $e_{i j k}$ random residual that is assumed to be normally distributed with mean zero and variance $\sigma^{2}$. Respective broad sense heritability $\left(H^{2}\right)$ for each trait across environments was computed as:

$$
H^{2}=\frac{\sigma_{V}^{2}}{\sigma_{v}^{2}+\frac{\sigma_{V x E}^{2}}{n}+\frac{\sigma_{e}^{2}}{r n}}
$$

Where, $\sigma_{V}^{2}$ the variance component for variety; $\sigma_{V x E}^{2}=$ the variance for variety by environment interaction; $\sigma_{e}^{2}=$ the error variance; $n=$ the number of environments; and $r=$ the number of replications. Accordingly, best linear unbiased predictors (BLUPs) for each variety were extracted using the ranef function in lme4 package (Bates et al., 2015). Eventually, BLUPs were used to perform correlation analyses, compute selection index and estimate annual genetic gains for evaluated traits, as they provide better estimates of genotype performance for unbalanced datasets than fixed clone effects (Piepho et al., 2008).

A weight-free rank summation index (RSI) (Hallauer et al., 1988; Badu-Apraku et al., 2013) was used to rank variety performances based on nine traits: FRY, HI, DMC, CMDs, cassava mosaic disease incidence (CMDi), CBSDfi, CBSDfs, CBSDri, and CBSDrs. To estimate genetic gains, BLUPs were assigned to the year when the variety was released i.e., varieties specifically released in 1940, 1993, 1999, 2003, 2011, 2015, and the current candidate varieties of 2019. Because released years were unevenly distributed, traits were regressed on order of release year i.e., 1, 2, 3, 4, 5, 6, and 7 representing 1940, 1993, 1999, 2003, 2011, 2015, and 2019, respectively. Effects of order of release year were tested for linear and quadratic responses of evaluated traits by orthogonal polynomial contrasts to determine the model that would best fit the set of data for a specific trait.

Absolute gain for linear relationships was obtained following the statistical model: $y=a+b x$, where; $y$ is dependent variable; $x=$ independent variable (order of released year); $a=$ intercept; and $b$ regression slope, which is the absolute genetic gain per released order (de Felipe et al., 2016). The slope was thereafter divided by the number of years for the respective breeding period to determine the annual genetic gain. Relative gain was obtained by dividing the absolute annual gain by mean trait performance of oldest released year that served as the check.

For quadratic relationships, absolute annual gain was calculated as the slope between two released orders i.e., between 1 (1940) and 2 (1993), 2 (1993) and 3 (1999), and 3 (1999) and 4 (2003), etc divided by the number of years for the respective breeding period. Relative gain was obtained by dividing the absolute annual gain by mean trait performance of older released year for each specific breeding period. Thus genetic gains were assessed sequentially in phases and as an average.

\section{RESULTS}

\section{Trait Heritabilities}

Diseases (CMD and CBSD) and yield traits (DMC, HI, and FRYD) were differently affected by environment and genotypic effects (Table 2). For example, variety effects explained up to $96.4 \%$ of the total variance for CMD severity, while $<20 \%$ of total variance could be attributed to varieties for HI, DMC, and FRY. Indeed, highest heritability was registered for CMD $\left(H^{2}=0.96\right)$ and lowest registered for harvest index $\left(H^{2}=0.43\right)$. Overall, modest-high heritabilities i.e., $\mathrm{H}^{2}>0.4$ were observed for all evaluated traits (Table 2).

\section{Performance of Varieties Based on Rank Summation Index}

Based on RSI, the top performers were mostly candidate clones (UG120024, UG120193, UG120183, UG120198, and UG110164), 
TABLE 2 | Percentage of the total variance attributed to variety, environment and variety by environment interaction for evaluated traits.

\begin{tabular}{|c|c|c|c|c|c|c|c|c|c|}
\hline Source of variation & CMDi & CMDs & CBSDfi & CBSDfs & CBSDri & CBSDrs & DMC & HI & FRY \\
\hline Replicate/Environment & 0.0 & 0.5 & 11.4 & 11.2 & 0.0 & 6.1 & 4.3 & 0.0 & 11.8 \\
\hline Variety & 95.4 & 96.4 & 33.9 & 35.2 & 45.7 & 36.5 & 18.2 & 5.8 & 13.6 \\
\hline Environment & 0.4 & 0.0 & 43.6 & 39.2 & 22.1 & 12.3 & 60.3 & 86.7 & 63.0 \\
\hline Variety ${ }^{\star}$ Environment & 3.1 & 2.7 & 7.6 & 10.8 & 21.9 & 30.4 & 11.5 & 3.5 & 6.1 \\
\hline Residual & 1.1 & 0.4 & 3.5 & 3.6 & 10.3 & 14.7 & 5.7 & 4.0 & 5.5 \\
\hline Genotype/Genotype`Environment & 30.8 & 35.7 & 4.4 & 3.2 & 2.1 & 1.2 & 1.6 & 1.6 & 2.2 \\
\hline Broad-sense heritability $\left(\mathrm{H}^{2}\right)$ & 0.95 & 0.96 & 0.75 & 0.70 & 0.59 & 0.44 & 0.51 & 0.43 & 0.53 \\
\hline
\end{tabular}

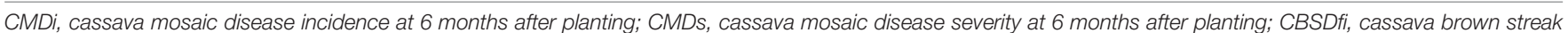

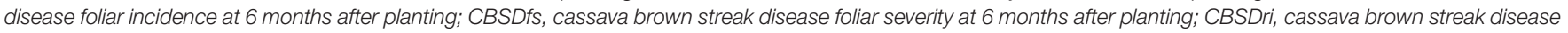

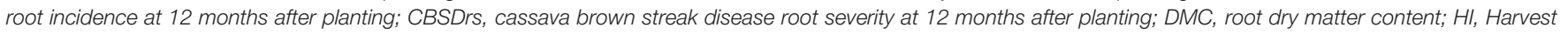
index; FRY, Fresh root yield. Analysis based on data collected in 2019 at three sites; Namulonge (central region), Serere (eastern region) and Loro (northern region).

and varieties officially released in 2011 (NASE 15), 1999 (NASE 4), 2015 (NAROCASS 1 and NAROCASS 2) and NASE 1 (1993) (Table 3). On the other hand, worst performers mostly comprised of popular local varieties (Magana, Nyaraboke, Bamunanika and Njure Red), and varieties released in 1993 (NASE 2 and NASE 3) or 2011 (NASE 13 and NASE 14). Both local varieties and varieties released in 1990s exhibited higher CMD and CBSD susceptibility compared to 2019 candidate clones or varieties released in 2015 (Tables 3, 4). Although varieties released in 2011 were generally resistant to $\mathrm{CMD}$ (incidence of $\leq 2.2 \%$ ), they were susceptible to CBSD (severity $\geq 2$ and incidence $\geq 41 \%$ ). Candidate clones exhibited high tolerance/resistance to CMD and CBSD as well as high DMC (Tables 3, 4).

\section{Genetic Gains for Disease Resistance and Yield Related Traits}

Cassava mosaic disease severity correlated negatively and significantly with order of release year $(r=-0.9, P<0.001)$ (Table 5). However, there was a negative non-significant correlation between CMD severity and CBSD foliar severity ( $r=-0.36, P=0.13$ ), and between CMD severity and CBSD root necrosis severity $(r=-0.40, P=0.08)$. CMD severity reduced from mean severity score of 3.5 (varieties released in 1940) to 1.3 (candidate clones of 2019), attaining an average annual genetic gain of $1.9 \%$ (Table 6). Highest annual gains were registered for 1993 to 1999 (5.2\%) and 1999 to 2003 (8.1\%). However, CMD susceptibility increased by $4.5 \%$ per year from 2015 to 2019.

For CBSD, we observed negative significant correlations between order of release year and CBSD foliar severity $(r=-0.74, P<0.001)$. Similar observations were made between order of release year and CBSD root necrosis severity $(r=-0.63$, $P<0.01$ ) (Table 5). CBSD foliar severity correlated positively and significantly with CBSD root necrosis severity $(r=0.67$, $P<0.01)$. CBSD foliar severity reduced from symptom severity score of 2.1 in 2003 to 1.3 in 2019 and thus attaining an average annual genetic gain of $2.3 \%$ (Table 6). Highest annual gains were recorded for 2015 to 20.19 (4.1\% per year). Similarly, CBSD root necrosis severity reduced from root necrosis score of 2.1 in 2003 to root necrosis score of 1.4 in 2019 and thus attaining an average annual genetic gain of $1.5 \%$.
Much as order of release year correlated positively and significantly with dry matter content $(r=0.40, P=0.02)$, we observed small, positive, nonsignificant correlations between order of release year and harvest index $(r=-0.11, P=0.53)$, plus fresh root yield $(r=0.07, P=0.73)$. Fresh root yield correlated positively and significantly with harvest index $(r=0.58$, $P<0.001)$. From 1940 to 2019 , root dry matter content increased linearly from 37.6 to $39.4 \%$ with a genetic gain of $0.1 \%$ per year. Fresh root yield increased from 17.1 tons per ha in 1940 to 25.5 tons per ha in 1999 with an average annual gain of $0.06 \%$. However, fresh root yield reduced from 25.6 tons/ha in 2003 to 18.6 tons/ha in 2019 at a rate of $0.12 \%$ per year (Table 6). Meanwhile, there were no genetic gains for harvest index between 1940 and 2019 (Figure 1).

\section{DISCUSSION}

Development and deployment of nutritious, stress-resilient, and high yielding cassava varieties requires identification and introgression of desirable alleles. As part of this process, routine assessment of genetic gain for key traits is necessary to identify gaps and quantify progress made toward attainment of prior defined breeding targets. Among the various methods for genetic gain assessment, growing released varieties in a common set of environments and regressing their trait means on year of release has gained popularity, as germplasm from recurrent selection programs is rarely available in breeding programs (Rutkoski, 2019). Accordingly, in this study, cassava varieties developed in Uganda between 1940 and 2019, were evaluated in 2019 to get insights into annual genetic gains. This was the first attempt to estimate genetic gain for selected cassava traits in Uganda.

Significant genotype variances were observed for all evaluated traits and thus, positively confirming the appreciable genetic variability in the evaluated clones and varieties (Ssemakula et al., 2000). The high heritabilities observed for disease traits are comparable to heritability estimates by Okul et al. (2018) and suggest that Namulonge (central Uganda) and Serere (eastern Uganda) are areas of high disease pressure for CMD and CBSD. Consistency in variety or clone rankings for CMD resistance could imply durability of resistance in the tested genotypes. 
TABLE 3 | Overall performance of clones based on rank summation index.

\begin{tabular}{|c|c|c|c|c|c|c|c|c|c|c|c|c|}
\hline Genotype & Year of release & CMDi & CMDs & CBSDfs & CBSDfi & CBSDrs & CBSDri & DMC & HI & FRY & RSI & Rank \\
\hline Bao & 1940 & 28 & 31 & 6 & 6 & 20 & 17 & 30 & 20 & 18 & 176 & 22 \\
\hline Bamunanika & 1940 & 25 & 27 & 21 & 17 & 30 & 29 & 21 & 6 & 11 & 187 & 27 \\
\hline Njure Red & 1940 & 30 & 32 & 29 & 28 & 10 & 11 & 13 & 8 & 20 & 181 & 23 \\
\hline Nyaraboke & 1940 & 31 & 28 & 30 & 31 & 9 & 7 & 23 & 28 & 32 & 219 & 32 \\
\hline NASE 1 & 1993 & 26 & 25 & 11 & 11 & 1 & 1 & 18 & 5 & 25 & 123 & 9 \\
\hline NASE 2 & 1993 & 21 & 22 & 26 & 22 & 21 & 26 & 24 & 13 & 8 & 183 & 24 \\
\hline NASE 3 & 1993 & 23 & 23 & 22 & 20 & 22 & 24 & 26 & 24 & 27 & 211 & 31 \\
\hline NASE 4 & 1999 & 12 & 9 & 15 & 19 & 4 & 6 & 28 & 2 & 5 & 100 & 6 \\
\hline NASE 5 & 1999 & 24 & 26 & 17 & 18 & 23 & 21 & 25 & 1 & 2 & 157 & 19 \\
\hline NASE 6 & 1999 & 13 & 15 & 31 & 27 & 16 & 20 & 27 & 9 & 26 & 184 & 26 \\
\hline NASE 13 & 2011 & 10 & 11 & 32 & 32 & 32 & 32 & 5 & 30 & 10 & 194 & 29 \\
\hline NASE 14 & 2011 & 2 & 4 & 24 & 29 & 31 & 31 & 15 & 32 & 24 & 192 & 28 \\
\hline NASE 15 & 2011 & 2 & 5 & 13 & 13 & 19 & 16 & 6 & 20 & 4 & 98 & 4 \\
\hline NASE 16 & 2011 & 2 & 1 & 18 & 16 & 26 & 28 & 17 & 18 & 6 & 132 & 12 \\
\hline NASE 18 & 2011 & 1 & 3 & 25 & 24 & 29 & 30 & 7 & 15 & 14 & 148 & 17 \\
\hline NASE 19 & 2011 & 2 & 5 & 19 & 21 & 28 & 25 & 11 & 14 & 15 & 140 & 14 \\
\hline NAROCASS 1 & 2015 & 15 & 13 & 16 & 15 & 11 & 10 & 16 & 3 & 3 & 102 & 7 \\
\hline NAROCASS 2 & 2015 & 8 & 5 & 8 & 10 & 12 & 14 & 14 & 25 & 31 & 127 & 10 \\
\hline UG120193 & 2019 & 18 & 18 & 3 & 3 & 4 & 8 & 2 & 16 & 7 & 79 & 2 \\
\hline UG120024 & 2019 & 9 & 1 & 6 & 7 & 3 & 3 & 3 & 9 & 28 & 69 & 1 \\
\hline UG110164 & 2019 & 16 & 16 & 5 & 5 & 13 & 13 & 22 & 6 & 9 & 105 & 8 \\
\hline
\end{tabular}

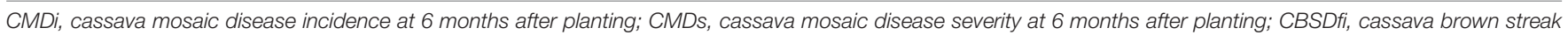

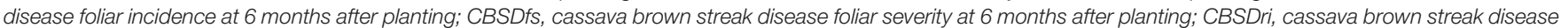

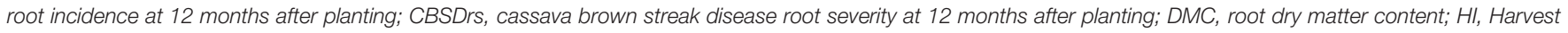

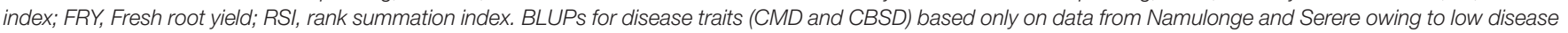
pressure at Loro. Genotypes were ranked based on their BLUP values for each trait.

TABLE 4 | Means for cassava traits selected for between 1940 and 2019 in Uganda.

\begin{tabular}{|c|c|c|c|c|c|c|c|}
\hline Year of release & No of Varieties & CMDs & DMC & $\mathrm{HI}$ & FRY & CBSDfs & CBSDrs \\
\hline 1940 & 7 & $3.5 \pm 0.2$ & $37.6 \pm 1.1$ & $0.37 \pm 0.03$ & $17.1 \pm 3.5$ & $1.8 \pm 0.2$ & $1.8 \pm 0.3$ \\
\hline 1993 & 3 & $2.3 \pm 0.3$ & $37.4 \pm 0.4$ & $0.40 \pm 0.003$ & $20.9 \pm 8.5$ & $2.0 \pm 0.3$ & $1.8 \pm 0.4$ \\
\hline 1999 & 3 & $1.6 \pm 0.6$ & $35.9 \pm 0.6$ & $0.45 \pm 0.01$ & $25.5 \pm 7.4$ & $2.1 \pm 0.2$ & $1.8 \pm 0.3$ \\
\hline 2003 & 3 & $1.4 \pm 0.2$ & $38.5 \pm 0.3$ & $0.38 \pm 0.01$ & $25.6 \pm 7.1$ & $2.1 \pm 0.2$ & $2.1 \pm 0.1$ \\
\hline 2011 & 6 & $1.1 \pm 0.02$ & $39.8 \pm 0.6$ & $0.30 \pm 0.02$ & $22.7 \pm 2.5$ & $2.2 \pm 0.2$ & $2.9 \pm 0.2$ \\
\hline 2015 & 2 & $1.1 \pm 0.1$ & $38.8 \pm 0.1$ & $0.40 \pm 0.07$ & $17.5 \pm 8.1$ & $1.7 \pm 0.5$ & $1.5 \pm 0.0$ \\
\hline 2019 & 8 & $1.3 \pm 0.1$ & $39.5 \pm 1.3$ & $0.30 \pm 0.02$ & $18.6 \pm 1.8$ & $1.3 \pm 0.1$ & $1.4 \pm 0.2$ \\
\hline
\end{tabular}

CMDs, cassava mosaic disease severity; DMC, dry matter content; HI, harvest index; FRY, fresh root yield; CBSDfs, cassava brown streak disease foliar severity; CBSDrs, cassava brown streak disease root severity.

Indeed, local and varieties released in 1990s consistently registered higher $\mathrm{CMD}$ susceptibility when compared to recent elite clones or varieties released in 2015 (Table 3). However, variety or clone rankings for CBSD resistance were not consistent across environments, possibly because there could be different cassava brown streak virus strains that are resident in test 
TABLE 5 | Pearson's correlation coefficients among selected cassava traits evaluated in cassava varieties released between 1940 and 2019 in Uganda.

\begin{tabular}{lcccccc}
\hline & DMC & CMDs & CBSDfs & CBSDrs & HI & FRY \\
\hline CMD6s & -0.21 & 1 & & & & \\
CBSDfs & -0.29 & -0.36 & 1 & & & \\
CBSDrs & -0.17 & -0.40 & $0.71^{\star \star \star}$ & 1 & & \\
HI & -0.21 & 0.07 & 0.03 & -0.34 & 1 & \\
FRY & 0.06 & -0.08 & 0.17 & 0.22 & $0.58^{\star \star \star}$ & 1 \\
Order of release year & $0.40^{\star}$ & $-0.9^{\star \star \star}$ & $-0.74^{\star \star \star}$ & $-0.63^{\star \star}$ & -0.11 & 0.07
\end{tabular}

CMD6s, cassava mosaic disease severity at 6 months after planting; CBSDfs, cassava brown streak disease severity at 6 months after planting; CBSDrs, cassava brown streak disease root necrosis severity at 12 months after planting; DMC, dry matter content; HI, harvest index; FRY, fresh root yield; ${ }^{\star} P<0.05$, ${ }^{* *} P<0.01$; ${ }^{* * *} P<0.001$. Correlations including CBSDfs and CBSDrs were performed using varieties or clones developed between 2003 and 2019 because selection for CBSD resistance began in 2003. Two sets of correlations were performed: (1) between evaluated traits and order of release year, and (2) amongst the evaluated traits across the released years.

environments. Cassava brown streak viruses [cassava brown streak virus (CBSV) and Uganda cassava brown streak virus (UCBSV)] have been reported to evolve rapidly, a phenomenon that could influence virulence (Ndunguru et al., 2015; Alicai et al., 2016) and thus amplify genotype by environment interactions (Pariyo et al., 2015; Okul et al., 2018). These findings further underpin the need for systematic evaluation and screening for CBSD in locations that are truly hotpots so as to discern resistant from susceptible clones.

Generally, candidate varieties and recently released varieties exhibited higher disease resistance (Tables 3, 4). Indeed, some of the candidate varieties e.g., UG120156 and UG120024 have also been reported by Okul et al. (2018) to exhibit high CBSD resistance. One possible explanation for this is that these candidate clones and/or varieties were selected for dual resistances to CMD and CBSD, which was not the case with varieties released before 2011. An exceptional clone was NASE
4, a variety released in 1999, which ranked among the top 10 performers; its ability to maintain superior and stable performance over a wide range of environments could explain this trend (Adriko et al., 2011).

Local varieties such as Magana (popular in eastern region), Nyaraboke (popular in mid-western region), Bamunanika (popular in central region) and Njure Red (popular in central region), were among the worst performers. These varieties showed high susceptibility to both CMD and CBSD (Tables 3, 4). It is important to note that these local varieties were among the first CMD resistant clones developed in 1930s in Amani (Tanzania) and introduced into Uganda in the 1940s for cultivation (Legg and Thresh, 2000). These clones were deployed for production in 1950s and formed a major part of the cassava production system in Uganda until the 1980s (Otim-Nape et al., 2001), when a second wave of CMD caused by co-infection of African Cassava Mosaic Virus (ACMV) and the recombinant strain of the East African Cassava Mosaic Virus (EACMVUG) emerged (Patil and Fauquet, 2009). The breakdown of CMD resistance in local varieties and varieties released in early 1990s (Table 3) is likely due to the long exposure to viruses or synergistic infections from the different cassava mosaic germiniviruses (CMGs).

Following the CBSD outbreak in Uganda in the early 2000s (Alicai et al., 2007), efforts were initiated to develop and release varieties that combine both CMD and CBSD resistance. The first batch of these varieties were officially released in 2011, all in an effort to limit spread and damage inflicted by CBSD. Notable of these were: NASE 14, NASE 15, NASE 16, NASE 18, and NASE 19. However, in the present study, these varieties maintained CMD resistance, but succumbed to CBSD, as exhibited in their respective CBSD foliar incidence (Table 4). Given that this assessment was done 8 years after these varieties were released, it is likely that the high root necrosis severity scores (Tables 3, 4) are a reflection of increased virus load accumulating in the vegetative tissues during this propagation

TABLE 6 | Genetic gains for cassava traits selected for between 1940 and 2019 in Uganda.

\begin{tabular}{|c|c|c|c|c|c|c|c|c|c|c|c|c|}
\hline \multicolumn{3}{|c|}{ Breeding period } & \multicolumn{5}{|c|}{ Absolute annual gain } & \multicolumn{5}{|c|}{ Relative annual gain (\%) } \\
\hline From & To & No. of years & CMDs & DMC & CBSDfs & CBSDrs & FRY & CMD & DMC & CBSDfs & CBSDrs & FRY \\
\hline 1993 & 1999 & 6 & -0.12 & 0.033 & 0.010 & 0.010 & $20 \mathrm{~kg}$ & -5.20 & 0.09 & 0.50 & 0.56 & 0.10 \\
\hline 1999 & 2003 & 4 & -0.13 & 0.050 & 0.000 & 0.000 & $15 \mathrm{~kg}$ & -8.10 & 0.14 & 0.00 & 0.00 & 0.06 \\
\hline 2003 & 2011 & 8 & -0.03 & 0.025 & -0.010 & -0.008 & $0.0 \mathrm{~kg}$ & -1.80 & 0.06 & -0.48 & -0.38 & 0.00 \\
\hline \multicolumn{3}{|c|}{ Average genetic gain } & -0.04 & 0.035 & -0.04 & -0.03 & $-5 \mathrm{~kg}$ & -1.90 & 0.10 & -2.30 & -1.50 & -0.03 \\
\hline \multicolumn{3}{|c|}{ Adjusted $R^{2}$ linear } & 0.63 & 0.16 & 0.14 & 0.02 & 0.02 & & & & & \\
\hline \multicolumn{3}{|c|}{ Adjusted $R^{2}$ quadratic } & 0.85 & 0.10 & 0.41 & 0.18 & 0.079 & & & & & \\
\hline
\end{tabular}

CMDs, cassava mosaic disease severity at 6 months; DMC, dry matter content; CBSDfs, cassava brown streak disease foliar severity at 6 months after planting; CBSDrs, cassava brown streak disease root severity at 12 months after planting; FRY, fresh root yield; $R^{2}$, coefficient of determination of the relationship between order of release year and the changes in traits over the years. Average annual gains (absolute and relative) for resistance to CBSD were computed using estimates from 2003 to 2019 because selection for the trait only began in 2003. There were no genetic gains for harvest index between 1940 and 2019. With the exception of DMC where genetic gains were estimated using slope of linear regression, annual genetic gains for all other traits were estimated using the slope between two released orders from the quadratic graphs, because the quadratic model provided higher $R^{2}$ values. 
A

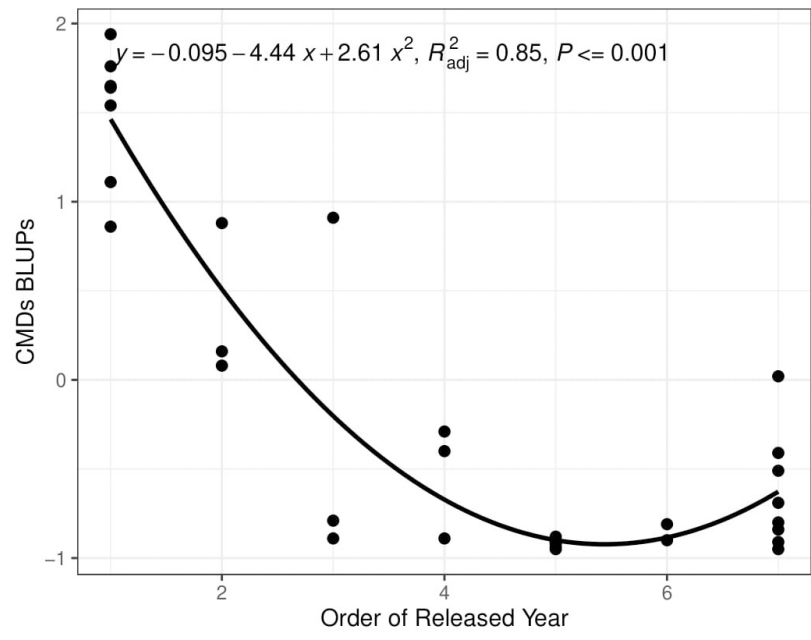

C

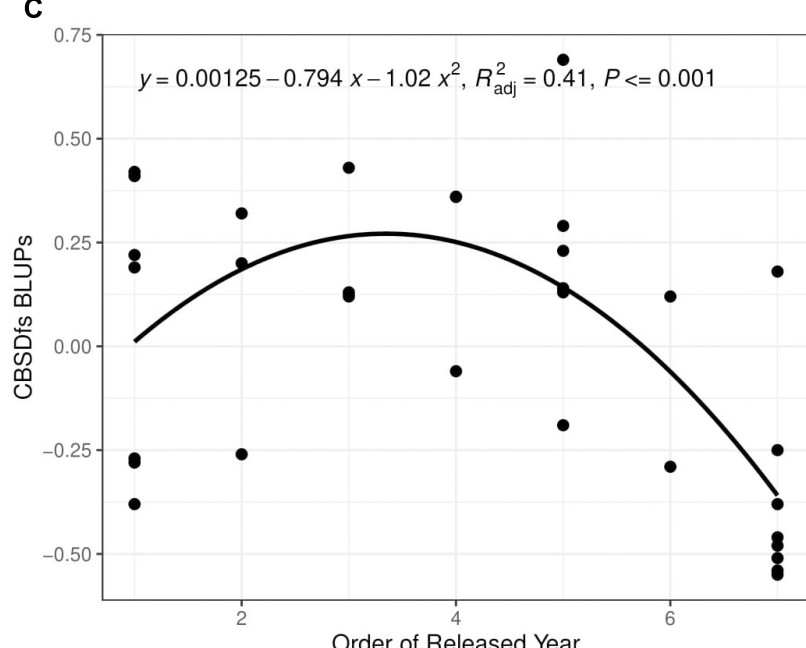

E

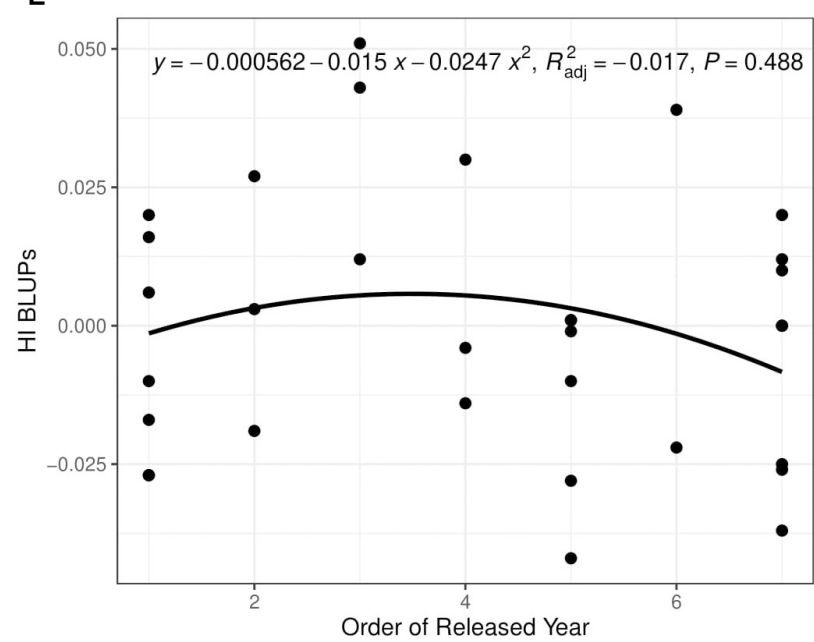

B

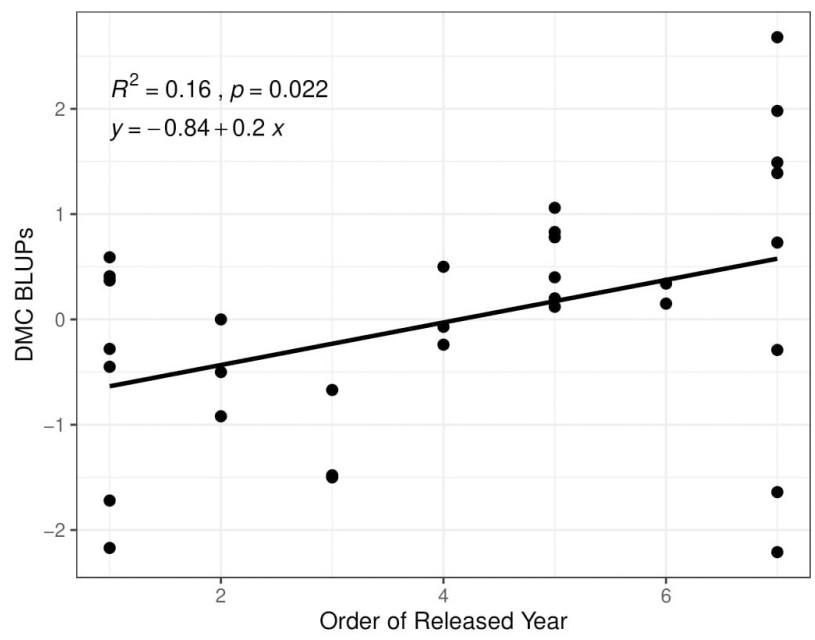

D

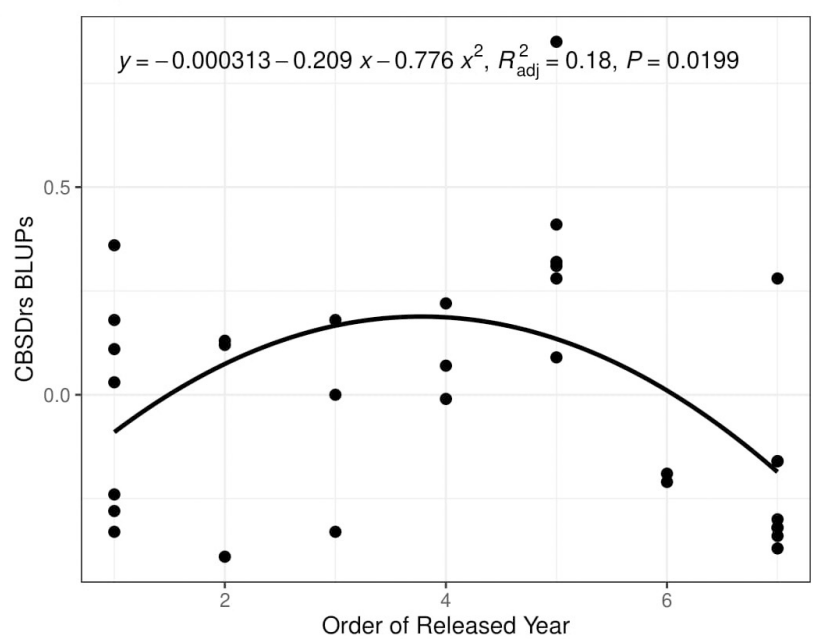

$\mathbf{F}$

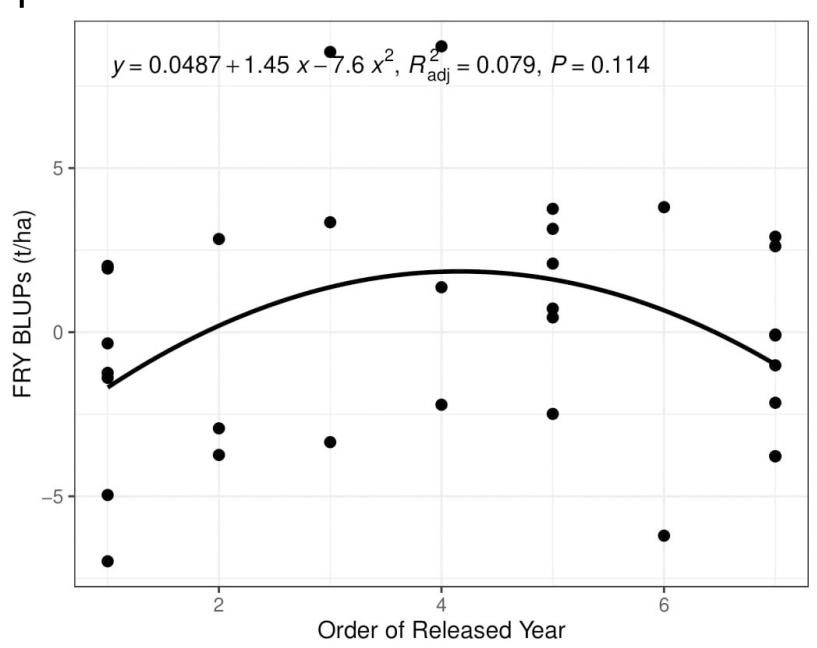

FIGURE 1 | Changes in yield and disease severity for 32 varieties released and/or developed between 1940 and 2019 in Uganda. (A) Cassava mosaic disease severity at 6 months after planting (CMDs). (B) Dry matter content (DMC). (C) Cassava brown streak disease foliar severity at 6 months after planting (CBSDfs). (D) Cassava brown streak disease root necrosis severity at 12 months after planting (CBSDrs). (E) Harvest index (HI). (F) Fresh root yield (FRY). CBSD resistance breeding was initiated in fourth released year (2003). 
period (Shirima et al., 2019). Similar observations were made by Mukiibi et al. (2018) and Okul et al. (2018), who reported that NASE 14 (released in 2011) registered high CBSD foliar and root incidence and severity after 6 years of release. This situation may be attributed to changes in the composition of virus species and/or virulence that overwhelms host defense systems and cause resistance breakdown or degeneration (Shirima et al., 2019). The clonal nature of cassava propagation amplifies this problem.

Correlation analyses were performed to assess relationships between order of release year and traits evaluated (Table 5). The significant linear relationships between order of release year and CMD resistance plus dry matter content suggest that breeding efforts between 1940 and 2019 were successful in developing CMD resistant genotypes with high dry matter content. Significant negative correlations between order of release year and CBSD resistance also suggest that breeding efforts undertaken between 2003 and 2019 majorly focused on development and/or release of CBSD resistant varieties. The small nonsignificant correlations between order of release year and yield-related traits (FRY and $\mathrm{HI}$ ) are indicative of preferential selection and release of genotypes with more emphasis placed on disease resistances as compared yield.

Direct selection for disease resistance without similar efforts devoted to yield-traits could explain the non-significant positive correlations between CBSD resistance with FRY or HI. On the other hand, high significant positive correlation between CBSD foliar and CBSD root necrosis severity, could imply that both traits were directly selected for, as witnessed by their respective reductions across years of release. Negative nonsignificant correlations between CBSD resistance and CMD resistance between 2003 and 2019, could suggest that high levels of CMD resistance had been attained at the time when selection for CBSD resistance was initiated, and therefore, most of the clones were tolerant to CMD, but had not attained similar levels of resistance for CBSD.

Based on regression analyses, CMD severity reduced by an average of $1.9 \%$ per year between the period 1940 and 2019. This genetic gain estimate is higher than that provided by Okechukwu and Dixon (2008), who reported $0.65 \%$ genetic gain per year for CMD resistance among IITA clones developed in Nigeria between 1970 and 2000. The highly significant genetic gain per year for CMD resistance could be explained in three ways. Firstly, breeding efforts targeting CMD resistance have been ongoing since 1930s (Legg and Thresh, 2000), which is sufficient time for increasing the frequency of resistance alleles in the breeding population through recurrent selection (Hallauer et al., 1988). Secondly, CMD resistance is largely governed by additive genetic effects (Hahn et al., 1980; Wolfe et al., 2016; Rabbi et al., 2020), which makes it amenable to genetic gains from recurrent selection. Thirdly, that deployed CMD resistance was effective against the prevalent cassava mosaic germiniviruses. Indeed, latest findings by Mukiibi et al. (2018) have showed that both single and coinfection of ACMV and EACMV-UG do exist in Uganda. The $4.5 \%$ increase in CMD susceptibility between 2015 and 2019 may be attributed to tradeoffs during selection for combined resistance to CBSD and CMD or use of CBSD resistant parents that are deficient in CMD resistance.
Much as research efforts to combat CBSD began in early 2000s when the disease had attained epidemic status in Uganda (Alicai et al., 2007), some varieties like NASE 1 that were released in 1993, exhibited high CBSD tolerance (Table 3). This finding could indicate that CBSD resistance alleles were present in IITA germplasm, from which NASE 1 was derived. Since 2003 when systematic CBSD resistance improvement began, there were average genetic gains of $2.3 \%$ per year for CBSD foliar resistance, and $1.5 \%$ per year for CBSD root necrosis resistance (Table 6). These genetic gains for CBSD resistance within such a relatively short timeframe could be attributed to the concerted and systematic approaches taken to harness and utilize available genetic resources in cassava breeding (Abaca et al., 2012; Kaweesi et al., 2014; Pariyo et al., 2015; Kawuki et al., 2016; Okul et al., 2018; Ozimati et al., 2018). Predominance of additive gene effects for CBSD resistance (Kulembeka et al., 2012; Chipeta et al., 2018), which can be exploited through recurrent selection, have equally enabled consolidation of gains.

Between 1940 and 2019, generally $5 \mathrm{~kg}$ per ha per year were lost for fresh root yield and no genetic gains in harvest index were observed; equally low genetic gains were recorded for dry matter content $(0.1 \%$ per year) (Table 6). This is contrary to findings from earlier studies by Okechukwu and Dixon (2008), and Ceballos et al. (2020), who reported annual genetic gains of $1.2 \%$ and $1.0 \%$ for fresh root yield in Nigeria and Thailand, respectively. Differences in selection strategies customized to address local needs in Uganda, Nigeria and Thailand could explain this variation. For example, breeding programs in South East Asia have for long, mainly focused on developing cassava clones with high yield and root quality traits such as starch (Ceballos et al., 2020). Similarly, cassava breeding programs in West Africa (Nigeria) have focused on development of cassava clones that combine high fresh root yield, root quality and CMD resistance (Manyong et al., 2000). In Uganda, however, critical traits selected for include; dual resistance to CMD and CBSD, high yield and desirable root quality (Kawuki et al., 2016). Certainly, selection for several traits limits genetic progress as it leads to compromising tradeoffs amongst target traits. For example, before CBSD emerged in Uganda, fresh root yield increased from 17.1 tons in 1940 to 25.6 tons in 2003 (Table 4). However, when CBSD attained epidemic status in the early 2000s, fresh root yield reduced from 25.6 tons in 2003 to 18.6 tons in 2019. Another good example is the sharp contrast between fresh root yield and CBSD resistance observed in clones UG120024 and UG120156 (Table 3).

\section{CONCLUSION}

The study described herein was conducted to estimate annual genetic gains for critical cassava traits that have been selected for between 1940 and 2019 in Uganda. Based on the generated datasets, this study revealed that there was significant annual genetic improvement of cassava for resistance to CMD and CBSD. Findings from the present study also demonstrated that the annual rate of genetic gain for cassava yield in Uganda is not sufficient to achieve the desired output necessary to reach the 
cassava production demand predicted for 2050. This underpins the urgent need to incorporate simultaneous selection for disease resistance and high yield for the crop to meet its current and futuristic demands for food and industry.

\section{DATA AVAILABILITY STATEMENT}

The original contributions presented in the study are included in the article/Supplementary Material, further inquiries can be directed to the corresponding author.

\section{AUTHOR CONTRIBUTIONS}

FM involved in data collection, analysis, and the manuscript writing. PR and PG involved in review and supervision. AO and WE involved in data collection, the manuscript editing, and review. $\mathrm{AB}$ and $\mathrm{CO}$ involved in review. TA involved in the manuscript review and editing. RK involved in data collection, analysis, the manuscript editing, and review and funding acquisition. All authors contributed to the article and approved the submitted version.

\section{REFERENCES}

Abaca, A., Kawuki, R., Tukamuhabwa, P., Baguma, Y., Pariyo, A., Alicai, T., et al. (2012). Evaluation of local and elite Cassava genotypes for resistance to cassava brown streak disease in Uganda. J. Agron. 11, 65-72. doi: 10.3923/ja.2012. 65.72

Adriko, J., Sserubombwe, W. S., Adipala, E., Bua, A., Thresh, J. M., and Edema, R. (2011). Response of improved cassava varieties in Uganda to cassava mosaic disease (CMD) and their inherent resistance mechanisms. Afr. J. Agric. Res. 6, 521-531.

Alicai, T., Ndunguru, J., Sseruwagi, P., Tairo, F., Okao-Okuja, G., Nanvubya, R., et al. (2016). Cassava brown streak virus has a rapidly evolving genome: implications for virus speciation, variability, diagnosis and host resistance. Sci. Rep. 6, 1-14. doi: 10.1038/srep36164

Alicai, T., Omongo, C. A., Maruthi, M. N., Hillocks, R. J., Baguma, Y., Kawuki, R., et al. (2007). Re-emergence of cassava brown streak disease in uganda. Plant Dis. 91, 24-29. doi: 10.1094/PD-91-0024

Alicai, T., Szyniszewska, A. M., Omongo, C. A., Abidrabo, P., Okao-okuja, G., Baguma, Y., et al. (2019). Expansion of the cassava brown streak pandemic in Uganda revealed by annual field survey data for 2004 to 2017. Sci. Data 6, 1-8. doi: 10.1038/s41597-019-0334-9

Badu-Apraku, B., Yallou, C. G., and Oyekunle, M. (2013). Genetic gains from selection for high grain yield and Striga resistance in early maturing maize cultivars of three breeding periods under Striga -infested and Striga -free environments. Field Crops Res. 147, 54-67. doi: 10.1016/j.fcr.2013. 03.022

Bates, D., Mächler, M., Bolker, B. M., and Walker, S. C. (2015). Fitting linear mixedeffects models using lme4. J. Statist. Softw. 67:51. doi: 10.18637/jss.v067.i01

Ceballos, H., Rojanaridpiched, C., Phumichai, C., Becerra, L. A., Kittipadakul, P., Iglesias, C., et al. (2020). Excellence in cassava breeding: perspectives for the future. Crop Breed Genet. Genom. 2:e200008.

Chipeta, M. M., Melis, R., and Shanahan, P. (2018). Gene action controlling cassava brown streak disease resistance and storage root yield in cassava. Euphytica 214, 1-15. doi: 10.1007/s10681-018-2196-1

de Felipe, M., Gerde, J. A., and Rotundo, J. L. (2016). Soybean genetic gain in maturity groups III to V in Argentina from 1980 to 2015. Crop Sci. 56, 3066-3077. doi: 10.2135/cropsci2016.04.0214

Esuma, W., Nanyonjo, A. R., Miiro, R., Angudubo, S., and Kawuki, R. S. (2019) Men and women's perception of yellow-root cassava among rural farmers

\section{FUNDING}

Funding for this work was provided by Cornell University through a sub-award agreement (N0. 84941-11038) between NaCRRI and Cornell University. This work was funded by Cornell University through "Next Generation Cassava Breeding Project."

\section{ACKNOWLEDGMENTS}

Special thanks go to the field-based staff of NaCRRI's Root Crops Program for assistance in trial establishment, management, and data collection.

\section{SUPPLEMENTARY MATERIAL}

The Supplementary Material for this article can be found online at: https://www.frontiersin.org/articles/10.3389/fpls.2021. 651992/full\#supplementary-material

in eastern Uganda. Agric. Food Security 8, 1-9. doi: 10.1186/s40066-0190253-1

Food and Agriculture Organization of the United Nations (FAOSTAT) (2019). FAOSTAT Statistical Database. Rome: FAO.

Fungo, B., Grunwald, S., Tenywa, M. M., and Vanlauwe, B. (2011). Lunnyu soils in the lake victoria basin of uganda: link to toposequence and soil type. Afr. J. Env. Sci. Technol. 5, 15-24.

Gibson, R. W., Legg, J. P., and Otim-Nape, G. W. (1996). Unusually severe symptoms are a characteristic of the current epidemic of mosaic virus disease of cassava in Uganda. Ann. Appl. Biol. 128, 479-490. doi: 10.1111/j.1744-7348. 1996.tb07108.x

Gondwe, F. M. T., Mahungu, N. M., Hillocks, R. J., Raya, M. D., Moyo, C. C., Soko, M. M., et al. (2003). "Economic losses experienced by small-scale farmers in malawi due to cassava brown streak virus disease," in Proceedings of the an International Workshop, eds J. P. Legg and R. J. Hillocks (Kenya), 27-30.

Hahn, S. K., Terry, E. R., and Leuschner, K. (1980). Breeding cassava for resistance to cassava mosaic disease. Euphytica 29, 673-683. doi: 10.1007/BF00023215

Hallauer, A. R., Carena, M. J., and Filho, M. J. B. (1988). Quantitative Genetics in Maize Breeding. Berlin: Springer, doi: 10.1007/978-1-4419-0766-0

Hillocks, R. J., Raya, M. D., Mtunda, K., and Kiozia, H. (2001). Effects of brown streak virus disease on yield and quality of cassava in Tanzania. J. Phytopathol. 149, 389-394. doi: 10.1046/j.1439-0434.2001.00641.x

IITA. (1990). Cassava in Tropical Africa. A Reference Manual. United Kingdom: Chayce Publication Services.

Iragaba, P., Nuwamanya, E., Wembabazi, E., Baguma, Y., Dufour, D., Earle, E. D., et al. (2019). Estimates for heritability and consumer-validation of a penetrometer method for phenotyping softness of cooked cassava roots. Afr. Crop Sci. J. 27, 147-163.

Isabirye, M., Mwesige, D., Ssali, H., Magunda, M., and Lwasa, J. (2004). Soil resource information and linkages to agricultural production. Uganda J. Agric. Sci. 9, 215-221.

Kawano, K., Daza, P., Amaya, A., Rios, M., and Goncalves, W. M. F. (1978). Evaluation of cassava germplasm for productivity. Crop Sci. 18, 377-380. doi: 10.2135/cropsci1978.0011183X001800030006x

Kawano, K., Fukuda, W. M. G., and Cenpukdee, U. (1987). Genetic and environmental effects on dry matter content of cassava root. Crop Sci. 27, 69-74. doi: 10.2135/cropsci1987.0011183x002700010018x

Kaweesi, T., Kawuki, R., Kyaligonza, V., Baguma, Y., Tusiime, G., and Ferguson, M. E. (2014). Field evaluation of selected cassava genotypes for cassava brown 
streak disease based on symptom expression and virus load. Virology J. 11:216. doi: 10.1186/s12985-014-0216-x

Kawuki, R. S., Kaweesi, T., Esuma, W., Pariyo, A., Kayondo, I. S., Ozimati, A., et al. (2016). Eleven years of breeding efforts to combat cassava brown streak disease. Breed. Sci. 66, 560-571. doi: 10.1270/jsbbs.16005

Kulembeka, H. P., Ferguson, M., Herselman, L., Kanju, E., Mkamilo, G., Masumba, E., et al. (2012). Diallel analysis of field resistance to brown streak disease in cassava (Manihot esculenta Crantz) landraces from Tanzania. Euphytica 187, 277-288. doi: 10.1007/s10681-012-0730-0

Legg, J. P., and Thresh, J. M. (2000). Cassava mosaic virus disease in East Africa: a dynamic disease in a changing environment. Virus Res. 71, 135-149. doi: 10.1016/S0168-1702(00)00194-5

Manyong, V. M., Makinde, K. O., Bokanga, M., and Whyte, J. (2000). The Contribution of IITA-Improved Cassava to Food Security in Sub-Saharan Africa: an Impact Study. Nigeria: International Institute of Tropical Agriculture.

Mukiibi, D. R., Alicai, T., Kawuki, R., Okao-Okuja, G., Tairo, F., Sseruwagi, P., et al. (2018). Resistance of advanced cassava breeding clones to infection by major viruses in Uganda resistance of advanced cassava breeding clones to infection by major viruses in Uganda. Crop Protection 115, 104-112. doi: 10.1016/j.cropro.2018. 09.015

Ndunguru, J., Sseruwagi, P., Tairo, F., Stomeo, F., Maina, S., Djinkeng, A., et al. (2015). Analyses of twelve new whole genome sequences of cassava brown streak viruses and ugandan cassava brown streak viruses from east africa: diversity, supercomputing and evidence for further speciation. PLoS One 10:e0141939. doi: 10.1371/journal.pone.01 39321

Nsubuga, F. W. N., Botai, O. J., Olwoch, J. M., Rautenbach, C. J., Bevis, Y., and Adetunji, A. O. (2014). The nature of rainfall in the main drainage subbasins of Uganda. Hydrol. Sci. J. 59, 278-299. doi: 10.1080/02626667.2013. 804188

Okechukwu, R. U., and Dixon, A. G. O. (2008). Genetic gains from 30 years of cassava breeding in Nigeria for storage root yield and disease resistance in elite cassava genotypes. J. Crop Improvement 22, 181-208. doi: 10.1080/ 15427520802212506

Okul, V. A., Ochwo-Ssemakula, M., Kaweesi, T., Ozimati, A., Mrema, E., Mwale, E. S., et al. (2018). Plot based heritability estimates and categorization of cassava genotype response to cassava brown streak disease. Crop Protection 108, 39-46. doi: 10.1016/j.cropro.2018.02.008

Orek, C., Gruissem, W., Ferguson, M., and Vanderschuren, H. (2020). Morphophysiological and molecular evaluation of drought tolerance in cassava (Manihot esculenta Crantz). Field Crops Res. 255:107861. doi: 10.1016/j.fcr.2020. 107861

Ortiz, R., and Nassar, N. M. A. (eds) (2007). "Cassava improvement to enhance livelihoods in sub-saharan africa and northeastern brazil," in Proceeding of the First International Meeting on Cassava Breeding, Biotechnology and Ecology.

Otekunrin, O., and Sawicka, B. (2019). Cassava, a 21st century staple crop: how can nigeria harness its enormous trade potentials? Acta Sci. Agric. 3, 194-202. doi: 10.31080/asag.2019.03.0586

Otim-Nape, G. W., Alicai, T., and Thresh, M. J. (2001). Changes in the incidence and severity of Cassava mosaic virus disease, varietal diversity and cassava production in Uganda. Ann. Appl. Biol. 138, 313-327.

Ozimati, A., Kawuki, R., Esuma, W., Kayondo, S. I., Pariyo, A., Wolfe, M., et al. (2019). Genetic variation and trait correlations in an East African Cassava breeding population for genomic selection. Crop Sci. 59, 460-473. doi: 10.2135/ cropsci2018.01.0060

Ozimati, A., Kawuki, R., Esuma, W., Kayondo, I. S., Wolfe, M., Lozano, R., et al. (2018). Training population optimization for prediction of cassava brown streak disease resistance in west african clones. G3-Genes Genom. Genet. 12, 3903-3913. doi: 10.1534/g3.118.200710

Pariyo, A., Baguma, Y., Alicai, T., Kawuki, R., Kanju, E., Bua, A., et al. (2015). Stability of resistance to cassava brown streak disease in major agro-ecologies of Uganda. J. Plant Breed. Crop Sci. 7, 67-78. doi: 10.5897/jpbcs2013. 0490

Patil, B. L., and Fauquet, C. M. (2009). Cassava mosaic geminiviruses: actual knowledge and perspectives. Mol. Plant Pathol. 10, 685-701. doi: 10.1111/j. 1364-3703.2009.00559.x

Piepho, H., Möhring, J., Melchinger, A. E., and Büchse, A. (2008). BLUP for phenotypic selection in plant breeding and variety testing. Euphytica 161, 209-228. doi: 10.1007/s10681-007-9449-8

Prakash, A. (2018). Cassava Market Developments and Outlook. In Food OutlookBiannual Report on Global Food Markets. Rome: Food and Agriculture Organization of United Nations. doi: 10.1044/leader.PPL.19102014.18

R Core Team. (2019). R: A Language and Environment for Statistical Computing. Vienna: R Foundation for Statistical Computing.

Rabbi, Y. I., Kayondo, S. I., Bauchet, G., Yusuf, M., Aghogho, I. C., Ogunpaimo, K., et al. (2020). Genome-wide association analysis reveals new insights into the genetic architecture of defensive, agro-morphological and quality-related traits in cassava. Plant Mol. Biol. doi: 10.1007/s11103-020-01038-3 [Epub ahead of print].

Rutkoski, J. E. (2019). Estimation of realized rates of genetic gain and indicators for breeding program assessment. Crop Sci. 59, 981-993. doi: 10.2135/cropsci2018. 09.0537

Shirima, R. R., Maeda, D. G., Kanju, E. E., Tumwegamire, S., Ceasar, G., Mushi, E., et al. (2019). Assessing the degeneration of cassava under high-virus inoculum conditions in coastal tanzania. Plant Dis. 103, 2652-2664. doi: 10.1094/PDIS05-18-0750-RE

Shittu, T. A., Alimi, B. A., Wahab, B., Sanni, L. O., and Abass, A. B. (2016). "Cassava flour and starch: processing technology and utilization," in Tropical Roots and Tubers: Production, Processing and Technology, eds H. K. Sharma, N. Y. Njintang, R. S. Singhal, and P. Kaushal 415-450. doi: 10.1002/9781118992739. ch10a

Spilke, J., Piepho, H., and Xiyuan, H. (2005). A simulation study on tests of hypotheses and confidence intervals for fixed effects in mixed models for blocked experiments with missing data. J. Agric. Biol. Environ. Statist. 10, 374-389. doi: 10.1198/108571105X58199

Ssemakula, G. N., Baguma, Y., Van der Grif, R., Otim-Nape, G. W., and Orone, J. (2000). Improvement of local cassava germplasm in Uganda. Uganda J. Agric. Sci. 5, 8-11.

Storey, H. H., and Nichols, R. F. W. (1938). Studies of the mosaic disease of cassava. Ann. Appl. Biol. 25, 790-806. doi: 10.1111/j.1744-7348.1938.tb02354.x

Tumuhimbise, R., Shanahan, P., and Melis, R. (2014). Combining ability analysis of storage root yield and related traits in cassava at the seedling evaluation stage of breeding. J. Crop Improvement 28, 530-546. doi: 10.1080/15427528.2014. 923798

Wagaba, H., Beyene, G., Cynthia, T., Alicai, T., Fauquet, C. M., and Taylor, N. J. (2013). Efficient transmission of cassava brown streak disease viral pathogens by chip bud grafting. BMC Res. Notes 6:516.

Wolfe, M. D., Rabbi, I. Y., Egesi, C., Hamblin, M., Kawuki, R., Kulakow, P., et al. (2016). Genome-wide association and prediction reveals genetic architecture of cassava mosaic disease resistance and prospects for rapid genetic improvement. Plant Geno. 9, 1-13. doi: 10.3835/plantgenome2015.11.0118

Conflict of Interest: The authors declare that the research was conducted in the absence of any commercial or financial relationships that could be construed as a potential conflict of interest.

Copyright (c) 2021 Manze, Rubaihayo, Ozimati, Gibson, Esuma, Bua, Alicai, Omongo and Kawuki. This is an open-access article distributed under the terms of the Creative Commons Attribution License (CC BY). The use, distribution or reproduction in other forums is permitted, provided the original author(s) and the copyright owner(s) are credited and that the original publication in this journal is cited, in accordance with accepted academic practice. No use, distribution or reproduction is permitted which does not comply with these terms. 